\title{
Burden, Health and Quality of Life of Nigerian Stroke Caregivers
}

\section{Akosile CO ${ }^{1 *}$, Okoye EC ${ }^{1}$, Adegoke $\mathrm{BOA}^{2}$, Mbada $\mathrm{CE}^{3}$, Maruf $\mathrm{FA}^{1}$ and Okeke $\mathrm{IA}^{1}$}

${ }^{1}$ Medical Rehabilitation Department, College of Health Sciences, Nnamdi Azikiwe University, Nnewi Campus, Anambra State, Nigeria

${ }^{2}$ Physiotherapy Department, College of Medicine, University of Ibadan, Ibadan, Nigeria

${ }^{3}$ Medical Rehabilitation Department, College of Health Sciences, Obafemi Awolowo University, Ile-Ife, Osun State, Nigeria

\begin{abstract}
Caring for a stroke survivor could become burdensome and may negatively affect the caregiver's health and quality of life (QOL). Studies from African populations depicting the relationship between burden of caregiving and the health and QOL of the caregivers are rather rare. The level of burden of caring for stroke survivors among informal stroke caregivers in Nigeria and its relationships to their QOL and its components was investigated in this study.

This was a secondary analysis of data from a descriptive cross-sectional survey of 91 (55 males, 36 females) volunteer caregivers of stroke survivors recruited from purposively sampled tertiary health facilities in South-Eastern Nigeria. The Carers' Strain Index and the Short Form 12-item Health Survey were used for estimating carers' burden, and QOL and its components respectively. Data was analysed with frequency and percentages, mean and standard deviation and Mann-Whitney $\mathrm{U}$ test $(\mathrm{p} \leq 0.05)$.

Majority (83.5\%) of the caregivers reported a high level of burden. QOL was most severely affected in the role limitation due to emotional problems and general health domains, though overall QOL score was modest. QOL scores were significantly lower for caregivers with high level of burden overall $(p=0.01)$ and in the Mental $(p=0.04)$ and Physical $(p=0.01)$ Component Summaries.

High level of burden among stroke caregivers portends serious consequences for their health and quality of life. While the physical consequences may be more easily observed in the presence of higher burden, emotional problems may more severely undermine role functioning. Attempts by clinicians to ameliorate carers' burden may be necessary for sustaining good health and QOL among the group. Attention should be particularly placed on their psychological/ emotional needs. These may be achieved with inclusion of appropriate handling techniques in caregivers education plan and providing adequate emotional support and counselling.
\end{abstract}

Keywords: Stroke; Caregiver; Burden; Health; Quality of life

\section{Introduction}

Informal care provision presents many challenges particularly among caregivers of stroke survivors [1,2]. The resultant permanent physical, cognitive and emotional changes from stroke affliction create pressure and life-changing demands for families and caregivers of its survivors [2,3]. Family caregivers are the ones who often bear the brunt of long-term care of stroke survivors and are thus likely to experience stress, burden and psychological morbidity [3]. Studies have reported high level of burden among stroke caregivers and also shown this to be associated with factors like degree of disability or stroke severity, post-stroke duration, gender of survivor, caregiver's age, gender and relationship with survivor among others [1,3-7].

The burden of care giving could become as excessive as to impact negatively on the caregivers' health and predispose them to the risk of burnout [8]. Burnout in caregivers has been reported to lead to a decrease in their quality of life and the quality of care they can deliver [9]. Reduction in stroke caregivers' health-related QOL is well reported [9-13]. Increased caregiver mortality and morbidity during the first year after stroke has been reported [14] and both the physical and mental health of the caregiver are affected [7]. Caregivers may experience new health conditions which may include musculoskeletal, skin, cardiovascular, infection and gastrointestinal conditions as well as fatigue and sleep problems [2,7,15]. Emotional disturbances experienced by caregivers could be in the form of anxiety, depression, fear, frustration, resentment, impatient and guilt $[2,16]$.

Studies have generally found negative relationships between caregivers' burden and QOL [10,11,17-19]. Wyller et al. [19] found this relationship to be stronger than that between QOL and patients' functional status while Morimoto et al. [10] found higher level of burdens to be the greatest predictor of caregivers' QOL. Though in previous works, we had reported level of burden and quality of life among Nigerian stroke caregivers $[6,13]$, no known work from Nigeria yet had examined the relationship between the burden of caring and QOL of caregivers of stroke survivors and similar studies from other African population are rare. The relationships among level of burden (LB), overall quality of life (QOL) and its physical and mental health components in a sample of Nigerian stroke caregivers were investigated in this study.

\section{Methodology}

This was a secondary analysis of data from a descriptive crosssectional survey of 91 (55 males, 36 females) volunteer caregivers of stroke survivors recruited from purposively sampled tertiary health facilities in South-Eastern Nigeria reported in previous works $[6,13]$. The original study was a survey of level of burden and quality of life and related factors in a Nigerian population of informal stroke caregivers.

*Corresponding author: Akosile Christopher Olusanjo, Medical Rehabilitation Department, Nnamdi Azikiwe University, Nnewi Campus, Anambra State, Nigeria Tel: +234-8028991825; E-mail: coakosile@yahoo.com, c.akosile@unizik.edu.ng

Received September 16, 2013; Accepted October 14, 2013; Published October 16,2013

Citation: Akosile CO, Okoye EC, Adegoke BOA, Mbada CE, Maruf FA, et al. (2013) Burden, Health and Quality of Life of Nigerian Stroke Caregivers. Health Care Current Reviews 1: 105. doi: 10.4172/2375-4273.1000105

Copyright: (C) 2013 Akosile CO, et al. This is an open-access article distributed under the terms of the Creative Commons Attribution License, which permits unrestricted use, distribution, and reproduction in any medium, provided the original author and source are credited. 
Approval was obtained from the Ethical Committee of Nnamdi Azikiwe University Teaching Hospital (NAUTH/CS/66/VOL.3/57) and individual participant gave written and verbal consent after due explanation of the study's procedure. Inability to speak and understand English Language and unwillingness to participate in the study were the only exclusion criteria.

Oral interview was used for obtaining information on the bio-data of the 91 caregivers ( 55 females, 36 males) whose mean age was 34.63 \pm 13.98 years. One of the authors (ECO) conducted the interviews and instrument administration along with trained research assistants and was present in each centre at the time of data collection. Carers' Strain Index (CSI) was used to assess caregivers' level of burden (LB) while Short Form 12 item Health Survey questionnaire (SF-12) was used to evaluate caregivers' quality of life. SF-12 has 8 domains: General Health (GH), Physical Function (PF), Role Limitation Due to Physical Function (RP), Bodily Pain (BP), Mental Health (MH), and Role Limitation Due to Emotional Health (RE), Social Function (SF) and Vitality (VT). It also has two broad components - physical (PCS) and mental (MCS) summary scores [20]. PCS consists of GH, PF, RP and BP domains while MCS consists of MH, RE, SF and VT domains. Each of SF-12 (QOL) domains, PCS and MCS summary and overall scores ranges from 0-100, with a higher score indicating a better health status. Good construct validity and reliability of SF-12 has been reported [21]. Caregiver Strain Index (CSI) is a 13-item questionnaire that has at least one item for each of the following major domains: Employment, Financial, Physical, Social and Time. Positive responses to seven or more items on the index indicate a greater level of strain and presence of burden [21]. Each participant was ranked as either burdened or not. The CSI has been reported to have a high internal consistency (alpha $=0.86$ ).

Statistical analysis was done with SPSS (version 16), descriptive statistics of frequency counts, percentages, mean and standard deviation were used to summarise participants' bio-data, LB and quality of life scores (QOL, domain, PCS and MCS summary scores). Inferential statistics of Mann-Whitney U test was used to compare the quality of life scores of caregivers who had higher level of burden (CSI score $\geq$ 7 ) and those who had lower level of burden (CSI score $<7$ ). This nonparametric test was chosen as the data was not normally distributed based on its skewness.

\section{Result}

91 caregivers (55 females, 36 males) of 91 stroke survivors (42 females, 49 males) participated in this study. $54.55 \%$ (30) of the female caregivers were caring for female stroke survivors while $33.33 \%$ (12) of the male caregivers were caring for female stroke survivors. $56 \%$ and $35 \%$ of the caregivers were young adults (19-39 years) and middle-aged adults (40-64 years) respectively (Table 1 ).

Seventy-six caregivers (83.5\%) were significantly burdened (CSI score $\geq 7$ ), and the mean quality of life domain, overall, physical component summary (PCS) and mental component summary (MCS) scores were all above the median score of 50 except the Role Mental domain score $(48.68 \pm 48.97)$ of the group with higher level of burden. Caregivers with higher level of burden had significantly lower GH, BP, $\mathrm{MH}, \mathrm{MCS}, \mathrm{PCS}$ and QOL scores than those with low level of burden. Caregivers with high level of burden also had lower PF, RP, RM, SF and VT scores than those with low level of burden but the differences were not statistically significant (Table 2).

Female caregivers had significantly lower GH, MH and VT domain scores than their male counterparts (Table 3). A higher proportion of female caregivers compared to males $(90.91 \%$ versus $72.22 \%)$ were significantly burdened.

\section{Discussion}

The association between the level of burden and quality of life and its constituent domains in a sample of informal caregivers of stroke survivors was investigated in the present study. A high proportion (82.4\%) of the stroke caregivers experienced considerable burden; a finding that is consistent with previous reports $[2,22,23]$. However, the prevalence of considerable burden in the present study was slightly higher than values from previous studies $[2,22,23]$. Those previous studies were conducted in countries from regions (Europe, North America and Australia) with better economies and more functional health systems compared to Nigeria. The adverse effect of factors like lack of training in caregiving role, inadequate information on caregiving, lack of or inadequate support to caregivers, and financial problems on caregivers' burden is well-documented [24-28]. Many Nigerians live with hard economic realities and when this is coupled with poor institutional support, the caregivers' burden may become more pronounced. We reason that aside socioeconomic factors, the high proportion of female caregivers and caregivers of female survivors may have contributed to the high prevalence of burden in the present study. Higher levels of burden have been associated with the two groups $[2,6,10]$.

\begin{tabular}{|c|c|c|c|}
\hline & Variables & Frequency & Percentage (\%) \\
\hline \multirow[t]{2}{*}{ Gender of stroke survivors } & Male & 49 & 53.8 \\
\hline & Female & 42 & 46.2 \\
\hline \multirow[t]{2}{*}{ Gender of caregivers } & Male & 36 & 39.6 \\
\hline & Female & 55 & 60.4 \\
\hline \multirow[t]{5}{*}{ Relationship } & Spouse & 14 & 14.6 \\
\hline & Child/child in-law & 53 & 55.2 \\
\hline & Grandchildren & 9 & 9.4 \\
\hline & Other relatives & 11 & 11.5 \\
\hline & Others & 4 & 4.2 \\
\hline \multirow[t]{4}{*}{ Age of Caregivers } & Children/Teenager & 5 & 5.2 \\
\hline & Young adults & 51 & 53.1 \\
\hline & Middle age adults & 32 & 33.3 \\
\hline & Elderly & 3 & 3.1 \\
\hline
\end{tabular}

Other relatives: niece, nephew, cousin and siblings

Others: Friends and driver

Table 1: Demographic characteristics of the participants. 
Citation: Akosile CO, Okoye EC, Adegoke BOA, Mbada CE, Maruf FA, et al. (2013) Burden, Health and Quality of Life of Nigerian Stroke Caregivers. Health Care Current Reviews 1: 105. doi: 10.4172/2375-4273.1000105

Page 3 of 5

\begin{tabular}{|c|c|c|c|c|}
\hline Quality of life score & All Caregivers & Caregivers with High LB & Caregivers with Low LB & U \\
\hline GH & $58.78 \pm 27.73$ & $55.92 \pm 26.42$ & $73.33 \pm 30.57$ & 384.00 \\
\hline PF & $77.20 \pm 30.88$ & $75.33 \pm 30.96$ & $86.67 \pm 29.68$ & 436.50 \\
\hline RP & $65.93 \pm 45.87$ & $63.16 \pm 46.45$ & $80.00 \pm 41.40$ & 460.50 \\
\hline BP & $72.53 \pm 30.52$ & $68.75 \pm 31.66$ & $91.67 \pm 12.20$ & 340.00 \\
\hline MH & $66.70 \pm 17.13$ & $64.61 \pm 15.79$ & $77.33 \pm 20.17$ & 333.50 \\
\hline RE & $51.10 \pm 48.86$ & $48.68 \pm 48.97$ & $63.33 \pm 48.06$ & 482.00 \\
\hline SF & $65.11 \pm 32.68$ & $62.83 \pm 31.75$ & $76.67 \pm 35.94$ & 403.50 \\
\hline VT & $62.64 \pm 28.94$ & $60.53 \pm 28.28$ & $73.33 \pm 30.86$ & \\
\hline MCS & $61.39 \pm 22.29$ & $59.16 \pm 21.04$ & $72.67 \pm 25.66$ & \\
\hline PCS & $68.61 \pm 25.65$ & $65.79 \pm 25.07$ & $82.92 \pm 24.49$ & \\
\hline Q & $64.67 \pm 21.84$ & $62.08 \pm 21.40$ & $77.79 \pm 19.82$ & 38.00 \\
\hline
\end{tabular}

*: Significant at $\mathrm{P} \leq 0.05$

CSI: Caregiver Strain Index; LB: level of burden; GH: General Health; PF: Physical Function; RP: Role Limitation Due to Physical Function; BP: Bodily Pain; RE: Role Limitation Due to Emotional Health; SF: Social Function; VT: Vitality; MH: Mental Health; PCS: Physical Component Summary Scores; MCS: Mental Component Summary Scores; QOL total: Total Quality of Life Score

Table 2: Mann-Whitney $U$ table comparing the mean quality of life scores between caregivers with high (CSI score $\geq 7)$ and low $(C S I$ score $<7)$ level of burden.

\begin{tabular}{|c|c|c|c|c|}
\hline Quality of life score & Male Caregivers & Female Caregivers & $\mathbf{U}$ & $\mathbf{P}$ \\
\hline $\mathrm{GH}$ & $67.36 \pm 29.17$ & $53.18 \pm 25.48$ & 719.00 & $0.02^{*}$ \\
\hline PF & $77.78 \pm 30.92$ & $76.81 \pm 31.12$ & 966.50 & 0.83 \\
\hline RP & $70.83 \pm 45.31$ & $62.72 \pm 46.36$ & 894.50 & 0.36 \\
\hline BP & $69.44 \pm 30.53$ & $74.55 \pm 30.61$ & 893.0 & 0.41 \\
\hline $\mathrm{MH}$ & $71.67 \pm 17.48$ & $63.48 \pm 16.24$ & 741.50 & $0.04^{*}$ \\
\hline RE & $51.39 \pm 49.98$ & $50.91 \pm 48.58$ & 984.50 & 0.96 \\
\hline SF & $72.22 \pm 30.92$ & $60.45 \pm 33.23$ & 784.00 & 0.08 \\
\hline VT & $68.89 \pm 31.51$ & $58.55 \pm 26.63$ & 756.50 & $0.05^{*}$ \\
\hline MCS & $66.04 \pm 24.11$ & $58.34 \pm 20.67$ & 805.00 & 0.13 \\
\hline PCS & $71.35 \pm 27.69$ & $66.81 \pm 24.32$ & 849.00 & 0.25 \\
\hline QOL total & $68.70 \pm 23.21$ & $62.03 \pm 20.69$ & 818.50 & 0.16 \\
\hline
\end{tabular}

*: Significant at $\mathrm{P} \leq 0.05$

CSI: Caregiver Strain Index; LB: level of Burden; GH: General Health; PF: Physical Function;

RP: Role Limitation Due to Physical Function; BP: Bodily Pain; RE: Role Limitation Due to Emotional Health

SF: Social Function; VT: Vitality; MH: Mental Health; PCS: Physical Component Summary Scores; MCS: Mental Component Summary Scores; QOL total: Total Quality of Life Score.

Table 3: Mann-Whitney $U$ table comparing the mean quality of life scores between male and female caregivers of stroke survivors.

Caregivers' quality of life was affected in practically all domains with mean scores ranging between 51.10 and 77.20. Worst scores for caregivers were however observed in the role limitation due to emotional problems (RE) and general health $(\mathrm{GH})$ domains. Reduction in QOL and its domains is more pronounced among individuals reporting higher levels of burden. This finding is consistent with previous reports associating caregivers' burden with worsening health and health-related QOL $[2,7,10,29,30]$.

The mental component summary (MCS) was considerably lower than the physical component summary (PCS) for study participants suggesting that mental health-related QOL was more affected than the physical. This finding corroborates previous report identifying emotional problems as the major ones among stroke caregivers [29,3135]. The RE was particularly low either when observed generally for participants or for the individual groups of highly-burdened or lessburdened individuals. It thus seems that irrespective of the level of burden experienced, emotional problems associated with stroke caregiving, more than any other, undermines the capability of an individual to perform role functions. Though the MCS constituent domains scores were generally lower for individuals with higher burdens, only in the mental health $(\mathrm{MH})$ domain was the difference statistically significant. Significantly poorer scores for women in this domain unlike the others may have contributed to the difference between the two groups. Women are not just more likely to be burdened; they also suffer more emotional problems $[2,6,10,17,35]$. A high proportion of studied caregivers were immediate family members. We have suggested earlier that seeing their loved ones being weighed down by disabilities may be emotionally disturbing for close relatives [13]. We could not establish significant differences between those with high and low burden in the vitality and social function domains but scores were much lower for those with higher burden. This trend may be a pointer that increasing burden may be exacerbating the experience of fatigue among caregivers and undermining their ability to participate in social activities in line with previous reports $[31,33,34,36]$.

Observed differences in QOL scores between participants with high and low burden was highest in the PCS. Scores in the PCS constituent domains were generally lower for those with higher levels of burden. However, only in the general health and bodily pain domains were these differences significant. Studies have generally reported deterioration in caregivers' physical health with increasing burden $[33,37,38]$. Healthcare professionals in our environment tend to overlook the need to include guidance on appropriate lifting and bending technique in their caregivers' educational plan. An unschooled caregiver performing these activities with improper techniques is thus more likely predisposed to bodily pain from strain and sprain and to report poorer general health with prolonged and persistent bodily pain. Other authors have also reported increasing tendency for burnout and development of painful conditions among stroke caregivers $[16,18]$. Scores in the physical function and role limitation due to physical function were not so different between caregivers with high and low 
Citation: Akosile CO, Okoye EC, Adegoke BOA, Mbada CE, Maruf FA, et al. (2013) Burden, Health and Quality of Life of Nigerian Stroke Caregivers. Health Care Current Reviews 1: 105. doi: 10.4172/2375-4273.1000105

Page 4 of 5

burden levels in this study. These domains were also not so severely affected in the two groups, probably due to the relatively young age of the participants, majority of who are in their young- or middle-ages. Studies have shown caregivers in these age groups to be to be less prone to a reduction in physical functioning compared to their older counterparts $[13,17,23]$ The necessity to provide needed care to a love one may also be responsible for the good scores obtained in these domains in this study and that of Morimoto et al. [10].

This study did not investigate a causal relationship and findings were only extrapolated based on observed associations. Other limitations to the main study and the need to cautiously interprete its finding had been previously noted. This secondary analysis revealed the association between burden of caregiving, health and quality of life in a Nigerian stroke caregiver sample. While QOL of individuals with higher burden may be more reduced in all the constituent domains, the reduction is most pronounced for physical health-related QOL. Emotional problems associated with stroke caregiving are however more likely to interfere with role functioning irrespective of the level of burden. The observed association revealed a need to have intervention targeted at minimizing caregivers' burden focused on strategies for reducing physical strains when performing different caregiving tasks. More importantly, attention should be placed on the psychological/emotional needs of these caregivers. Including appropriate handling techniques in caregivers education plan and providing adequate emotional support to help improve caregivers' effectiveness in their often new roles is an important information for all healthcare professionals involved in stroke care.

\section{References}

1. Tiegs TJ, Heesacher M, Ketterson TU, Pekich DG, Rittman MR, et al. (2006) Coping by stroke caregivers: sex similarities and differences. Topics Stroke Rehabil 13: 52-62.

2. Nir Z, Greenberger C, Bachner Y G (2009) Profile, burden, and quality of life of Israeli stroke survivor caregivers: a longitudinal study. J Neurosci Nurs 41: 92-105.

3. Bhogal SK, Teasel RW, Foley NC, Speeechley MR (2003) Community reintegration after stroke. Topics Stroke Rehabil 10: 107-130.

4. Rombough RE, Howse EL, Bagg SD, Barfay WJ (2007) A comparison of quality of life of primary caregivers of stroke survivors: a systematic review of the literature. Topics Stroke Rehabil 14: 69-79.

5. Coombs UE (2007) Spousal caregiving for stroke survivors. J Neurosci Nurs 39: $112-119$.

6. Akosile CO, Okoye EC, Odunowo OK (2009) Carers' Burden in Stroke and Some Associated Factors in a South-Eastern Nigerian Population. African J Neuro Sci 28: 2.

7. Rittman M, Hinojosa MS, Findley K (2009) Subjective sleep, burden, depression, and general health among caregivers of veterans poststroke. $J$ Neurosci Nurs 41: 39-52.

8. Ski C, O'Connell B (2007) Stroke: the increasing complexity of carer needs. J Neurosci Nurs 39: 172-179.

9. Adams C (2003) Quality of life for caregivers and stroke survivors in the immediate discharge period. Applied Nurs Res 16: 126-130.

10. Morimoto T, Schreiner AS, Asano H (2003) Caregiver burden and health-related quality of life among Japanese stroke caregivers. Age and Ageing 32: 218-223.

11. Smith LN, Norrie J, Kerr SM, Lawrence I M, Langhorne P, et al. (2004) Related quality of life of post-stroke survivors' close relatives. Cerebrovas Dis 29: 373-379.

12. White C L, Poissant L, Cote-Leblanc G, Wood-Dauphine S (2006) Long-term caregiving after stroke: the impact on caregivers' QOL. J Neurosci Nurs 38: 354-360.

13. Akosile CO, Okoye EC, Nwankwo MJ, Akosile CO, Mbada CE (2011) Quality of life and its correlates in caregivers of stroke survivors from a Nigerian population. Qual Life Res 20: 1379-1384.

14. Cristakis NA, Allison PD (2006) Mortality after the hospitalization of a spouse. New Engl J Med 354: 719-730.

15. King RB, Carlson CE, Shade-Zedlow Y, Bares KK, Roth EJ, et al. (2001) Transition to home care after stroke. Depression, physical health, and adaptive processes in support persons. Res Nurs Health 24: 307-323.

16. Anderson CS, Linto J, Stewart-Wynne EG (1995) A population based assessment of the impact and burden of care-giving for long-term stroke survivors. Stroke 26: 843-849.

17. McCullagh E, Brigstocke G, Donaldson N, Kalra L (2005) Determinants of caregiving burden and quality of life in caregivers of post-stroke patients. Stroke 36: 2181-2186

18. Van den Heuvel E, de Witte LP, Schure LM, Sanderman R, Meyboom-de Jong B (2001) Risk factors for burn-out in caregivers of stroke patients, and possibilities for intervention. Clin Rehabil 15: 669-677.

19. Wyller TB, Thommesen B, Sodring KM, Sveen U, Pettersen AM et al. (2003) Emotional well-being of close relatives to stroke survivors. Clin Rehabil 17 410-417.

20. Steiner V, Pierce L, Drahuschak S, Nofziger E, Buchman D, et al. (2008) Emotional support, physical help, and health of caregivers of stroke survivors. J Neurosci Nurs 40: 48-54.

21. Sullivian MT (2002) Caregiver Strain Index (CSI), Hartford Institute Geriatric Nursi Bulletin No 1.

22. McCusker J, Latimer E, Cole M, Ciampi A, Sewitch M (2007) Major depression among medically ill elders contributes to sustained poor mental health in their informal caregivers. Age and Ageing 36: 400-406.

23. Nelson MM, Smith MA, Martinson CM, Kind A, Leupker RV (2008) Declining functioning and caregiver burden/health: The Minnesota stroke survey -quality of life after stroke study. Gerontol 48: 573-583.

24. Clemson L, Fitzgerald MH, Mullavey-O'Byrne C (1999) Medical grand rounds. Family perspectives following stroke: The unheard stories. Top Stroke Rehabil 6: 60-77.

25. Brereton L, Nolan M (2000) 'You do know he's had a stroke, don't you?' Preparation for family caregiving - the neglected dimension. J Clin Nurs 9 : 498-506.

26. Burman ME (2001) Family caregiver expectations and management of the stroke trajectory. Rehabil Nurs 26: 94-99.

27. Kerr S, Smith LN (2001) Stroke: An exploration of the experience of informal caregiving. Clin Rehabil 15: 428-436.

28. Bakas T, Austin JK, Okonkwo KF, Lewis RR, Chadwick L (2002) Needs concerns, strategies, and advice of stroke caregivers the first 6 months afte discharge. J Neurosci Nurs 34: 242-251.

29. White C L, Mayo N, Hanley JA, Wood-Dauphinee S (2003) Evaluation of the caregiving experience in the initial 2 years following stroke. Res Nurs Health 26: 177-189.

30. van Exel NJ, Koopmanschap MA, van den Berg B, Brouwer WB, van den Bos GA (2005) Burden of informal caregiving for stroke patients. Identification of caregivers at risk of adverse health. Cerebrovas Dis 19: 11-17.

31. Murray J, Ashworth R, Forster A, Young J (2003) Developing a primary carebased stroke service: A review of the qualitative literature. $\mathrm{Br} \mathrm{J}$ Gen Pract 53 137-142.

32. Visser-Meily A, Post M, Riphagen II, Lindeman E (2004). Measures used to assess burden among caregivers of stroke patients: A review. Clin Rehabil 18: 601-623.

33. McKevitt C, Redfern J, Mold F, Wolfe C (2004) Qualitative studies of stroke: A systematic review. Stroke 35: 1499-1505.

34. Lee RLT (2004) Caring for family members with stroke: Chinese family caregivers. Asian J Nurs Studies 7: 18-27.

35. Jonsson AC, Lindgren I, Hallstrom B, Norrving B, Lindgren A (2005) Determinants of quality of life in stroke survivors and their Informal caregivers. Stroke 36: 803-808. 
Citation: Akosile CO, Okoye EC, Adegoke BOA, Mbada CE, Maruf FA, et al. (2013) Burden, Health and Quality of Life of Nigerian Stroke Caregivers. Health Care Current Reviews 1: 105. doi: 10.4172/2375-4273.1000105

Page 5 of 5

36. Grant JS (2004) Caregiving problems and feelings experienced by family caregivers of stroke survivors the first month after discharge. Int J Rehabil Res 27: 105-111.

37. McPherson CJ, Wilson KG, Chyurlia L, Leclerc C (2011) The caregiving relationship and quality of life among partners of stroke survivors: a correlational study. Health Qual Life Outcomes 9: 29.

38. Subgranon R, Lund DA (2000) Maintaining caregiving at home: A culturally sensitive grounded theory of providing care in Thailand. J Transcult Nurs 11 : $166-173$. 